\title{
Malignant Extragastrointestinal Neuroectodermal Tumor Located at Right Cervical Region
}

\author{
Nil Çomunoğlu ${ }^{*}$, Sergülen Dervişoğlu1, Bilge Başkır Elçin¹, Gonca Ayşe Tekant ${ }^{2}$, \\ Hilmi Apak ${ }^{3}$ \\ ${ }^{1}$ Department of Pathology, Cerrahpaşa Faculty of Medicine, Istanbul University, Istanbul, Turkey \\ ${ }^{2}$ Department of Pediatric Surgery, Cerrahpaşa Faculty of Medicine, Istanbul University, Istanbul, Turkey \\ ${ }^{3}$ Department of Pediatric Hematooncology, Cerrahpaşa Faculty of Medicine, Istanbul University, Istanbul, Turkey \\ Email: ${ }^{*}$ ilustundag@yahoo.com
}

Received 1 September 2015; accepted 13 October 2015; published 16 October 2015

Copyright (C 2015 by authors and Scientific Research Publishing Inc.

This work is licensed under the Creative Commons Attribution International License (CC BY). http://creativecommons.org/licenses/by/4.0/

(c) () Open Access

\begin{abstract}
Malignant Gastrointestinal Neuroectodermal Tumor (GNET) is a recently described rare malignant neoplasm, resembling "clear cell sarcoma of tendons and aponeuroses" morphologically, immunohistochemically and molecular pathologically. We will describe a case of soft tissue sarcoma located at right cervical region of a 9-year-old male patient, mimicking malignant GNET, which can be considered as extragastrointestinal counterpart of this tumor. These tumors have poor prognosis. This is unique, possibly the first case of a soft tissue sarcoma resembling GNET.
\end{abstract}

\section{Keywords}

Gastrointestinal Neuroectodermal Tumor, Clear Cell Sarcoma, S-100 Protein

\section{Introduction}

Enzinger described clear cell sarcoma of tendons and aponeuroses (CCSTA) as a distinct entity in 1965 [1]. These tumors exhibited morphologic and immunohistocemical resemblance to malignant melanomas and therefore were referred to as "malignant melanoma of soft parts" [2] [3]. The discriminative feature of CCSTA from malignant melanoma is EWSR1/ATF1 $\mathrm{t}(12 ; 22)(\mathrm{q} 13 ; \mathrm{q} 12)$ gene translocation which is not seen in cutaneous melanomas. Rare tumors with similar morphologic, immunohistochemical and molecular genetic characteristics, originating from gastrointestinal tract, have been documented. Stockman et al. firstly described these neoplasms ${ }^{*}$ Corresponding author.

How to cite this paper: Çomunoğlu, N., Dervişoğlu, S., Elçin, B.B., Tekant, G.A. and Apak, H. (2015) Malignant Extragastrointestinal Neuroectodermal Tumor Located at Right Cervical Region. Open Journal of Pathology, 5, 125-128. 
as "malignant gastrointestinal neuroectodermal tumor (GNET)" also known as clear cell sarcoma-like gastrointestinal tumor (CCSLGT), in 2012 [4]. These tumors however do not show melanocytic features but neuronal differentiation appreciated by strong and diffuse S-100 immunopositivity. We herein this case report will present an extraordinary case, a tumor arising in extragastrointestinal soft tissue, resembling CCSLGT histopathologically and immunohistochemically.

\section{Case Report}

A 9-year-old male patient following because of hydrocephalus presented with mass lesion of right cervical region, located at cervical 2 (C2) region. The patient had not any other complaints or mass lesion. Core needle biopsies revealed a malignant tumor, therefore excisional biopsy was performed. Macroscopically tumor was measuring 5, $5 \times 5 \times 4 \mathrm{~cm}$. The lesion was encapsulated. Cut surface was solid, elastic in consistency and yellowish in color. Microscopically lesion was a mesenchymal tumor consisted of epitheloid cells with clear or pale eosinophilic cytoplasm, forming a nested (Figure 1 and Figure 2) or pseudoalveolar pattern. Tumor displayed pseudoalveolar and pseudopapillary morphology centrally. Nuclei of the tumoral cells had convoluted contours, vesicular chromatin, occasional pseunonuclear inclusions and small nucleoli. Mitotic index was 1 per 10 high power field (HPF). Necrosis was not observed. PAS and dPAS special stains were negative. Immunohistochemically tumoral cells were strongly and diffusely positive for S-100 (Figure 3). SOX10 showed focal nuclear

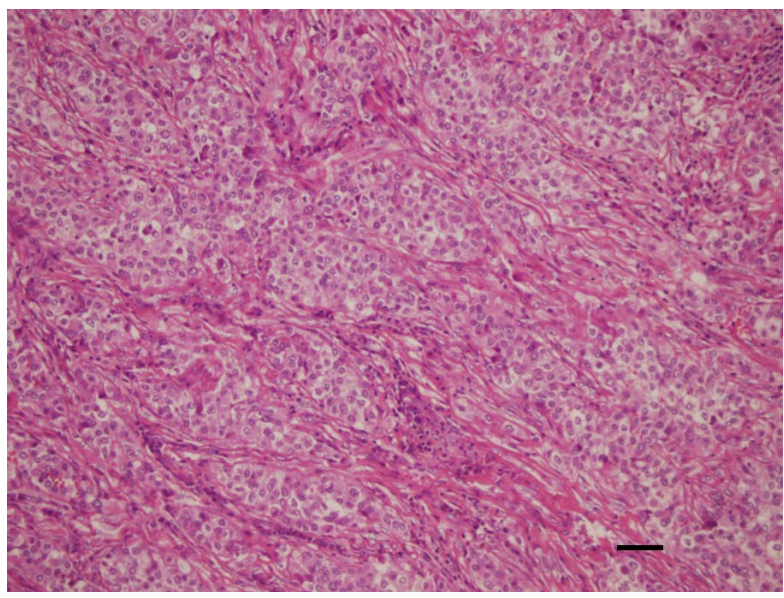

Figure 1. Epithelioid tumor cells with a distinctly nested morphology (H\&E; Scale bar: $25 \mu \mathrm{m})$.

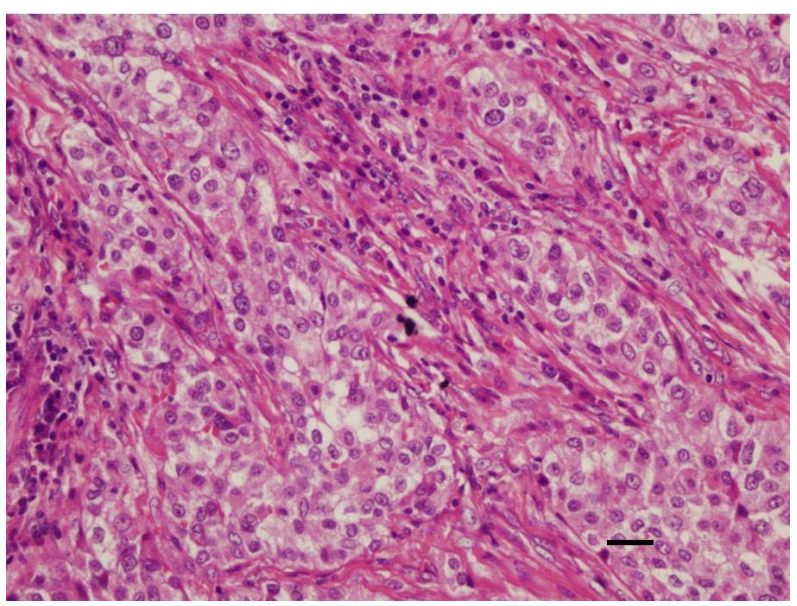

Figure 2. Tumor cells with oval to convoluted nuclear contours, vesicular chromatin, occasional small nucleoli and palely eosinophilic to clear cytoplasm (H\&E; Scale bar: $100 \mu \mathrm{m})$. 


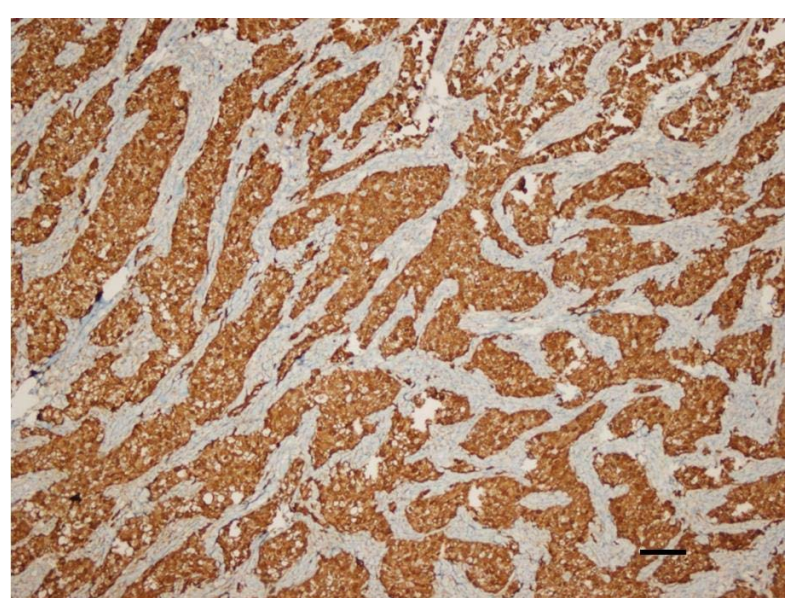

Figure 3. Tumor cells are immunopositive with S-100 (S100; Scale bar: $25 \mu \mathrm{m})$.

immunopositivity, mainly peripherally. HMB45, Melan A, MART-1, TTF1, EMA, pancytokeratin, cytokeratin AE1/AE3, CAM5.2, CK5/6, p63, CD31, SMA, desmin, synaptophysin, chromogranin, GFAP, CD68 and PR were negative. TTF-3 staining was nonspesific. Ki-67 proliferation index was $4 \%-5 \%$.

Fluorescence in situ hybridization (FISH) analysis to assess for rearrangement of the EWSR1 gene locus was attempted on the specimen but was technically unsatisfactory.

Chemotherapy was carried out. The patient is well without evidence of disease after 1 years of follow up.

\section{Discussion}

CCSTA is rare malignant soft tissue tumor [1] [5]. Recently, tumors entitled as "clear cell sarcoma-like tumor of the gastrointestinal tract (CCSLTGT)" have been described [6]. It has been reported that these tumors express S100 and SOX10 immunohistochemically [4]. These tumors show chromosome translocation t(12;22)(q13;q12) forming the fusion of EWSR1 and ATF1. They also display EWSR1 gene rearrangements. Stockman et al. suggested that these tumors immunohistochemically and ultrastructurally displayed evidence of neural differentiation and speculated that they originate from an autonomic nervous system related primitive cell of neural crest [4]. Authors stated that these tumors appear as a specific type of neuroectodermal tumor and therefore suggested the term "malignant gastrointestinal neuroectodermal tumor". We present in this report an extraordinary case of soft tissue sarcoma resembling malignant GNET, arising in a 9 year old male patient.

It has been reported that GNET occurs mainly in young and middle aged patients [4] [7]-[9]. Our patient was 9 years old.

Enzinger had reported that CCSTA showed multiple recurrences and metastasis [1]. It has been observed that GNEt also exhibit malignant behaviour with poor prognosis [4] [8]. The patient presented in this report had chemotherapy, is well and alive after 1-year follow-up.

Macroscopically, Enzinger described CCSTA as having well defined borders and a fibrous capsule. Cut surface was solid and gray-white in color [1]. GNETs are reported to have a lobulated, firm, tan-white cut-surface [4]. The lesion in our case was encapsulated.

Microscopically CCSTAs were reported to be composed of nests and fasicles of tumor cells which were epitheloid or fusiform having pale cytoplasms. Tumoral cell groups were surrounded by fibrous tissue. Nuclei were round, with prominent nucleoli. Multinucleated giant cells were present in most of the tumors. Mitotic index was observed to be low [1]. GNETs also contained epitheloid or oval to spindled cells forming nests or sheets. Tumor nuclei had vesicular chromatin and occasional intranuclear cytoplasmic inclusions. Mitotic figures were variable [4]. These tumors also showed pseudoalveolar, pseudopapillary, microcystic, fascicular and core-like patterns differing from CCSTA. Generally, as mentioned, these tumors are reported to resemble each other histopathologically. In our case morphology was similar to CCSTA and GNET, however we did not observe multinucleated giant cells, which is not an essential feature for these tumors.

Immunohistochemically CCSTA cases are positive for melanoma markers such as HMB-45, Melan-A and 
MiTF. However GNET differ from CCSTA in that they do not express these immunomarkers. Tumor in our case show similar immunomorphology with GNET being negative for HMB45, Melan A and MART-1.

For our case we tried to demonstrate the EWSR1 gene rearrangement by FISH, however because of technical problems unfortunately we could not manage.

For differential diagnosis monophasic synovial sarcoma and metastatic melanoma should also be considered. Immunohistochemical examination helps discriminating these tumors by showing negativity for melanoma and epithelial markers. Our case was also negative for epithelial markers EMA, pancytokeratin, cytokeratin AE1/ AE3 and CAM5.2, besides melanoma markers.

Our case is unique in that it is a soft tissue sarcoma resembling GNET, possibly the first case described in the English literature, displaying neuroectodermal morphological features but not exhibiting immunohistochemical melanoma characteristics, differing from CCSTA.

\section{Conclusion}

As a result, we think that "clear cell sarcoma-like tumor of the gastrointestinal tract (CCSLTGT)" can be seen at extragastrointestinal sites. Immunohistochemical positivity for S-100 and negativity for melanoma markers are characteristic findings for differential diagnosis.

\section{References}

[1] Enzinger, F.M. (1965) Clear-Cell Sarcoma of Tendons and Aponeuroses. An Analysis of 21 Cases. Cancer, 18, 11631174 .

[2] Chung, E.B. and Enzinger, F.M. (1983) A Reassessment of Clear Cell Sarcoma. The American Journal of Clinical Pathology, 7, 405-413. http://dx.doi.org/10.1097/00000478-198307000-00003

[3] Antonescu, C.R. (2013) Clear Cell Sarcoma of Soft Tissue. In: Fletcher, C.D.M., Bridge, J.A., Hogencloorn, P.C.W. and Mertens, F., Eds., WHO Classification of Tumours of Soft Tissue and Bone, 4th Edition, IARC Press, Lyon, 221222.

[4] Stockman, D.L., Miettinen, M., Suster, S., Spagnolo, D., Dominguez-Malagon, H., Hornick, J.L., Adsay, V., Chou, P.M., Amanuel, B., Vantuinen, P. and Zambrano, E.V. (2012) Malignant Gastrointestinal Neuroectodermal Tumor: Clinicopathologic, Immunohistochemical, Ultrastructural, and Molecular Analysis of 16 Cases with a Reappraisal of Clear Cell Sarcoma-Like Tumors of the Gastrointestinal Tract. The American Journal of Surgical Pathology, 36, 857868. http://dx.doi.org/10.1097/PAS.0b013e31824644ac

[5] Goldblum, J.R., Folpe, A.L. and Weiss, S.W. (2014) Clear Cell Sarcoma of Tendon and Aponeurosis. In: Goldblum, J.R., Folpe, A.L. and Weiss, S.W., Eds., Soft Tissue Tumors, Elsevier Saunders, Philadelphia, 886-894.

[6] Zambrano, E., Reyes-Mugica, M., Franchi, A. and Rosai, J. (2003) An Osteoclast-Rich Tumor of the Gastrointestinal Tract with Features Resembling Clear Cell Sarcoma of Soft Parts: Reports of 6 Cases of a GIST Simulator. International Journal of Surgical Pathology, 11, 75-81. http://dx.doi.org/10.1177/106689690301100202

[7] Kong, J., Li, N., Wu, S., Guo, X., Gu, C. and Feng, Z. (2014) Malignant Gastrointestinal Neuroectodermal Tumor: A Case Report and Review of the Literature. Oncology Letters, 8, 2687-2690.

[8] Thway, K., Judson, I. and Fisher, C. (2014) Clear Cell Sarcoma-Like Tumor of the Gastrointestinal Tract, Presenting as a Second Malignancy after Childhood Hepatoblastoma. Case Reports in Medicine, 2014, Article ID: 984369, 6 p. http://dx.doi.org/10.1155/2014/984369

[9] Yegen, G., Güllüoğlu, M., Mete, O., Onder, S. and Kapran, Y. (2015) Clear Cell Sarcoma-Like Tumor of the Gastrointestinal Tract: A Case Report and Review of the Literature. International Journal of Surgical Pathology, 23, 6167. http://dx.doi.org/10.1177/1066896914547046

\section{Abbreviations and Acronyms}

GNET: Gastrointestinal neuroectodermal tumor;

CCSTA: Clear cell sarcoma of tendons and aponeuroses;

CCSLGT: Clear cell sarcoma-like gastrointestinal tumor;

FISH: Fluorescence in situ hybridization;

CCSLTGT: Clear cell sarcoma-like tumor of the gastrointestinal tract. 